\title{
Initiate test loop irradiations of ALSEP process solvent
}

Dean R. Peterman, Lonnie G. Olson, Rocklan G. McDowell

September 2014

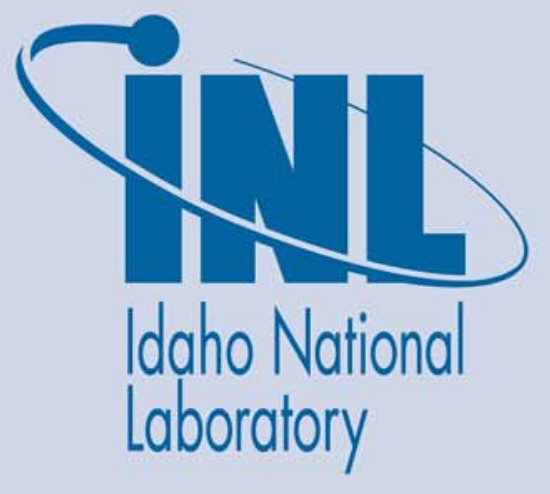

The INL is a U.S. Department of Energy National Laboratory operated by Battelle Energy Alliance 
INL/EXT-15-33325

\title{
Initiate test loop irradiations of ALSEP process solvent
}

Dean R. Peterman, Lonnie G. Olson, Rocklan G. McDowell

September 2014

\author{
Idaho National Laboratory \\ Idaho Falls, Idaho 83415
}

http://www.inl.gov

Prepared for the

U.S. Department of Energy

Office of Nuclear Energy

Under DOE Idaho Operations Office

Contract DE-AC07-05ID14517 


\section{Initiate test loop irradiations of ALSEP process solvent \\ Fuel Cycle Technology}

Prepared for

U.S. Department of Energy Material Recovery and Waste Form Development Dean R. Peterman, Lonnie G. Olson, Rocklan G. McDowell Idaho National Laboratory September 30, 2014 FCRD-SWF-2014-000206 



\section{DISCLAIMER}

This information was prepared as an account of work sponsored by an agency of the U.S. Government. Neither the U.S. Government nor any agency thereof, nor any of their employees, makes any warranty, expressed or implied, or assumes any legal liability or responsibility for the accuracy, completeness, or usefulness, of any information, apparatus, product, or process disclosed, or represents that its use would not infringe privately owned rights. References herein to any specific commercial product, process, or service by trade name, trade mark, manufacturer, or otherwise, does not necessarily constitute or imply its endorsement, recommendation, or favoring by the U.S. Government or any agency thereof. The views and opinions of authors expressed herein do not necessarily state or reflect those of the U.S. Government or any agency thereof. 



\section{SUMMARY}

This report describes the initial results of the study of the impacts of gamma radiolysis upon the efficacy of the ALSEP process and is written in completion of milestone M3FT-14IN030202. Initial irradiations, up to $100 \mathrm{kGy}$ absorbed dose, of the extraction section of the ALSEP process have been completed. The organic solvent used for these experiments contained 0.05 M TODGA and 0.75 M HEH[EHP] dissolved in $n$-dodecane. The ALSEP solvent was irradiated while in contact with $3 \mathrm{M}$ nitric acid and the solutions were sparged with compressed air in order to maintain aerated conditions. The irradiated phases were used for the determination of americium and europium distribution ratios as a function of absorbed dose for the extraction and stripping conditions. Analysis of the irradiated phases in order to determine solvent composition as a function of absorbed dose is ongoing. Unfortunately, the failure of analytical equipment necessary for the analysis of the irradiated samples has made the consistent interpretation of the analytical results difficult.

Continuing work will include study of the impacts of gamma radiolysis upon the extraction of actinides and lanthanides by the ALSEP solvent and the stripping of the extracted metals from the loaded solvent. The irradiated aqueous and organic phases will be analyzed in order to determine the variation in concentration of solvent components with absorbed gamma dose. Where possible, radiolysis degradation product will be identified. 


\section{CONTENTS}

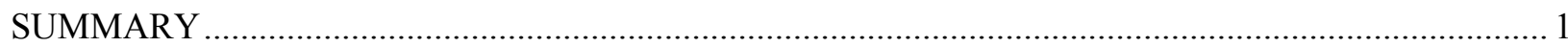

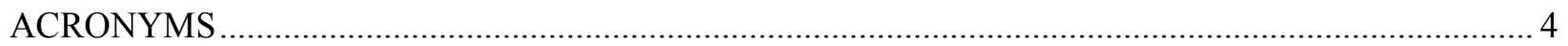

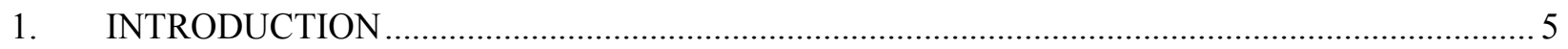

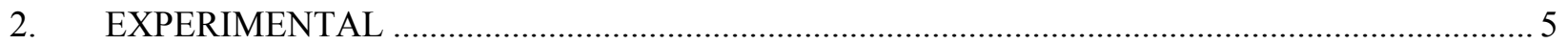

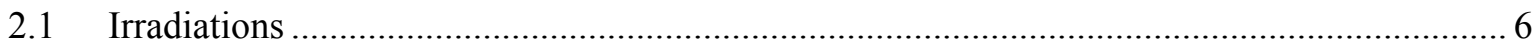

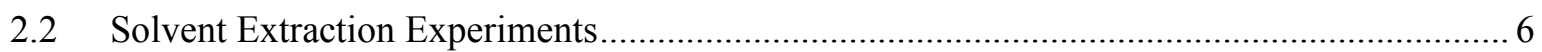

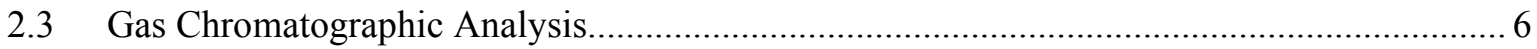

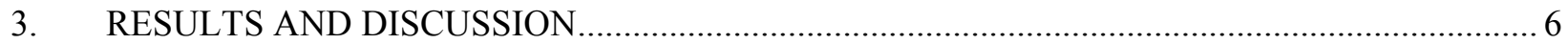

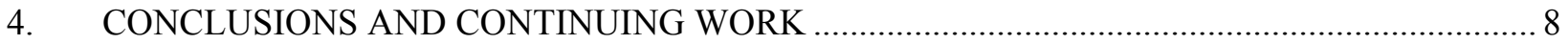

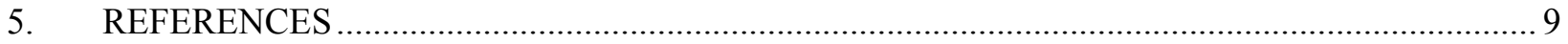

\section{FIGURES}

Figure 1. Structures of compounds used in the ALSEP process......................................................... 5

Figure 2. Calibration curve for the GC-FID analysis of TODGA. Equation of linear best-fit: $y=$ $3.281 \times 10^{-3} \mathrm{x}+2.087 \times 10^{-4}, \mathrm{R}^{2}=0.9985$. 8

TABLES

Table 1. Distribution ratios, $\mathrm{D}_{\mathrm{Am}}$ and $\mathrm{D}_{\mathrm{Eu}}$, determined using static irradiated ALSEP solvent and nitric acid. Organic: 0.05 M TODGA / 0.75 M HEH[EHP] / n-dodecane. Aqueous: 3 $\mathrm{M}$ nitric acid. 


\section{ACRONYMS}

ALSEP Actinide Lanthanide Separation

ANL Argonne National Laboratory

FCRD Fuel Cycle Research and Development program

GC-FID Gas Chromatography with Flame Ionization Detection

HEH[EHP] 2-ethyl(hexyl)phosphonic acid mono-2-ethylhexyl ester

HPGe High Purity Germanium detector

INL Idaho National Laboratory

$\mathrm{O} / \mathrm{A} \quad$ Organic to Aqueous phase volume ratio

PNNL Pacific Northwest National Laboratory

PUREX Plutonium Uranium Reduction Extraction

TALSPEAK Trivalent Actinide Lanthanide Separation by Phosphorous reagent Extraction from Aqueous Komplexes

TODGA $\quad N, N, N^{\prime}, N^{\prime}$-tetraoctyldiclycolamide

T2EHDGA $\quad N, N, N^{\prime}, N^{\prime}$-tetra(2-ethylhexyl)digylcolamide 


\section{INITIATE TEST LOOP IRRADIATIONS OF ALSEP PROCESS SOLVENT}

\section{INTRODUCTION}

Researchers at INL are studying the impacts of gamma radiolysis on the Actinide Lanthanide Separation (ALSEP) extraction process. The ALSEP process was developed through a joint collaboration between Argonne National Laboratory (ANL) and Pacific Northwest National Laboratory (PNNL). ${ }^{[1,2]}$ This process uses an organic solvent consisting of a neutral diglycolamide extractant, $N, N, N^{\prime}, N^{\prime}-$ tetraocylydiglycolamide (TODGA), and an acidic extractant 2-ethylhexylphosphonic acid mono-2ethylhexyl ester (HEH[EHP]) dissolved in an aliphatic diluent. The actinides and lanthanides are coextracted from relatively high nitric acid and the actinides are selectively stripped using a carboxylic acid buffered polyaminopolycarboxylic acid solution. The structures of the compounds used in the ALSEP process organic phase are depicted in Figure 1.

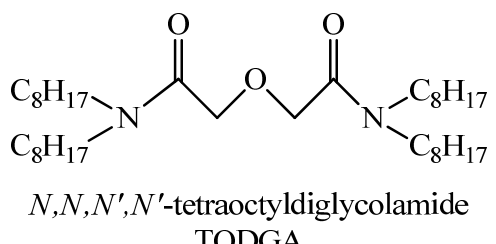

TODGA

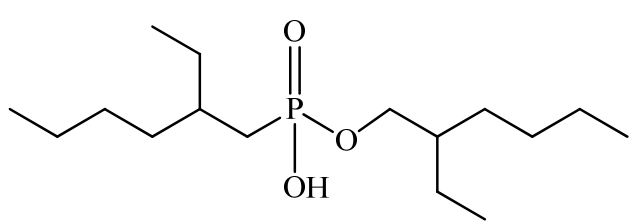

2-ethyl(hexyl)phosphonic acid mono-2-ethylhexyl ester $\mathrm{HEH}[\mathrm{EHP}]$

Figure 1. Structures of compounds used in the ALSEP process.

Initial irradiations, up to $100 \mathrm{kGy}$ absorbed dose, of the extraction section of the ALSEP process have been completed. The organic solvent used for these experiments contained $0.05 \mathrm{M}$ TODGA and $0.75 \mathrm{M}$ HEH[EHP] dissolved in $n$-dodecane. The ALSEP solvent was irradiated while in contact with $3 \mathrm{M}$ nitric acid and the solutions were sparged with compressed air in order to maintain aerated conditions. The irradiated phases were used for the determination of americium and europium distribution ratios as a function of absorbed dose for the extraction and stripping conditions. Analysis of the irradiated phases in order to determine solvent composition as a function of absorbed dose is ongoing. This report describes the initial results of the study of the impacts of gamma radiolysis upon the efficacy of the ALSEP process and is written in completion of milestone M3FT-14IN030202.

\section{EXPERIMENTAL}

All chemicals were reagent grade or higher and used without further purification except where noted. Aqueous solutions were prepared using de-ionized water (MilliQ, $18 \mathrm{M} \Omega$ ). All analyses are performed in triplicate unless otherwise noted. The neutral diglycolamide extractants, $N, N, N$ ' $N$ 'tetraoctyldiglycolamide (TODGA) and $N, N, N^{\prime} N^{\prime}$-tetra(2-ethylhexyl)diglycolamide (T2EHDGA) were purchased from Eichrom and used as received. The liquid cation exchanging extractant 2-ethyl(hexyl) phosphonic acid mono-2-ethylhexyl ester (HEH[EHP]) was obtained from a commercial source (YickVic Chemicals, China) and purified by a literature procedure. ${ }^{[3]}$ The final purity of the HEH[EHP] was greater than $98 \%$ based on ${ }^{31} \mathrm{P}$ NMR and potentiometric analyses. Reagent grade $n$-dodecane (99\%) was purchased from Aldrich and used as received. Concentrated nitric acid (70\%, w/w, Aldrich, Trace Metal Grade) was used to prepare the nitric acid solutions used in this work. Acid solutions were standardized by titration against standard base $(\mathrm{NaOH}$, Aldrich). 


\subsection{Irradiations}

The irradiation source used for these experiments was a MDS Nordion GammaCell 220 Excel selfcontained ${ }^{60} \mathrm{Co}$ gamma irradiator. The irradiated solutions were contained in air-sparged glass scintillation vials. Sparging was performed using a flow of compressed air $(1 \mathrm{sccm})$ supplied by mass flow controllers (Sierra, Model C50L). Samples of the ALSEP solvent (0.050 M TODGA + 0.75 M $\mathrm{HEH}[\mathrm{EHP}]$ ) were prepared volumetrically and pre-equilibrated three times with $3.0 \mathrm{M}$ nitric acid using an organic-to-aqueous phase volume ratio $(\mathrm{O} / \mathrm{A})$ of one. Aliquots of the pre-equilibrated organic phase and fresh 3.0 M nitric acid were irradiated at known positions in the GammaCell 220E sample chamber. The dose rate at known positions within the GammaCell 220E sample chamber was determined by Fricke dosimetry. ${ }^{[4,5]}$

\subsection{Solvent Extraction Experiments}

The effect of gamma radiolysis upon the extraction performance of irradiated aqueous and organic samples of ALSEP process solutions was evaluated by measuring americium and europium distribution ratios. The ${ }^{243} \mathrm{Am}$ radioisotope was obtained from Idaho National Laboratory (INL) stocks. The ${ }^{154} \mathrm{Eu}$ radiotracer was purchased from Eckert $\&$ Ziegler. The distribution ratio, $\mathrm{D}_{\mathrm{M}}$, was calculated as the ratio of the equilibrium concentration of the radiotracer in the organic phase to that in the aqueous phase. The metal distribution ratios were determined using irradiated aqueous and organic phases. After the addition of the radiotracers, the aqueous and organic phases were mixed for two minutes using a vortex mixer. Following vortex mixing, the samples were centrifuged to facilitate phase separation. Since the kinetics of stripping from the loaded ALSEP solvent were reported to be relatively slow, ${ }^{[1]}$ a four minute vortex mixing time was used for stripping studies. An aliquot of each phase was taken for radiometric analysis using gamma spectrometry. Radiometric analyses were performed using a Changer Lab 6000N sample changer equipped with an ORTEC GEM50P4 co-axial HPGe detector and DSPEC multichannel analyzer.

\subsection{Gas Chromatographic Analysis}

Due to the acidic functional group of the HEH[EHP] and the possibility of the generation of acidic degradation products, an aliquot of each solvent sample was diluted 100 fold with hexane and derivatized with $300 \mu \mathrm{L}$ of an $\sim 0.3 \mathrm{~mol} / \mathrm{L}$ solution of diazomethane in hexane prior to analysis. ${ }^{[6]}$ This produced the methyl ester of the phosphoric acid functional groups in the target compounds. These samples were analyzed along with appropriate calibration and quality assurance samples for HEH[EHP] and radiolytic degradation products.

The gas chromatography analyses were performed on a Thermo Scientific Trace ULTRA gas chromatograph. The chromatograms were processed using Thermo Scientific Xcalibur software. The chromatographic separations were carried out utilizing a Thermo Scientific TG-35MS capillary column $(30 \mathrm{~m} \times 0.32 \mathrm{~mm}$ ID $\times 0.5 \mu \mathrm{m}$ film). Analytical conditions were set at $2.0 \mathrm{~mL} / \mathrm{min}$ constant flow with helium as the carrier gas and an $80 \mathrm{~mL} / \mathrm{min}$ split flow. Oven operating conditions started with a $2 \mathrm{~min}$ hold at $70^{\circ} \mathrm{C}$, followed by a ramp at $20^{\circ} \mathrm{C} / \mathrm{min}$ to $240^{\circ} \mathrm{C}$ then $40^{\circ} \mathrm{C} / \mathrm{min}$ to $280^{\circ} \mathrm{C}$, finished with an 8.25 min hold at $280^{\circ} \mathrm{C}$. A Thermo AS3000 auto sampler was used for all injections, employing a $1 \mu \mathrm{L}$ hot injection with the inlet set at $250{ }^{\circ} \mathrm{C}$ and 5 second pre-injection dwell time. The FID was held constant at $250^{\circ} \mathrm{C}$. The fuel gas for the FID is a mixture of $350 \mathrm{~mL} / \mathrm{min}$ air and $35 \mathrm{~mL} / \mathrm{min}$ hydrogen with 30 $\mathrm{mL} / \mathrm{min}$ nitrogen as a makeup gas.

\section{RESULTS AND DISCUSSION}

Zarzana et al. ${ }^{[7]}$ used mass spectroscopic techniques to compare the $\gamma$-radiolysis of TODGA and T2EHDGA. In their work, solutions of diglycolamide extractants in n-dodecane were subjected to $\gamma$ irradiation in the presence or absence of an acidic aqueous phase and subsequently analyzed using 
electrospray ionization mass spectrometry. These authors reported an exponential decrease in the concentration of TODGA or T2EHDGA which was independent of the acidic aqueous phase. A number of radiolysis products were identified corresponding to the cleavage of bonds within the diglycolamide functionality; $\mathrm{C}-\mathrm{O}_{\text {ether }}, \mathrm{N}-\mathrm{C}_{\text {carbonyl }}, \mathrm{N}-\mathrm{C}_{\text {side-chain }}$ bonds, and to a lesser extent the $\mathrm{C}-\mathrm{C}_{\text {carbonyl }}$ bond. Sugo et al. ${ }^{[8]}$ Sharma et al. ${ }^{[9]}$ and Deepika et al. ${ }^{[10]}$ all reported similar radiolytic degradation products of either TODGA or T2EHDGA.

In order to evaluate the potential impacts of gamma radiolysis upon the efficacy of the ALSEP process, simple batch contact experiments were performed using aqueous and organic phases irradiated up to $100 \mathrm{kGy}$ absorbed dose. The actinides and lanthanides were co-extracted from relatively high nitric acid and the actinides were selectively stripped using a carboxylic acid buffered polyaminopolycarboxylic acid solution. The organic phase used in these experiments contained $0.05 \mathrm{M}$ TODGA $+0.75 \mathrm{M}$ $\mathrm{HEH}[\mathrm{EHP}]$ dissolved in n-dodecane and aqueous phase was $3 \mathrm{M}$ nitric acid. The organic composition was chosen based upon available literature. ${ }^{[1]}$ The nitric acid concentration was set at $3 \mathrm{M} \mathrm{HNO}_{3}$ since this acid concentration led to the highest extraction of lanthanum, which is the least extracted lanthanide ion by the ALSEP process. ${ }^{[1]}$ The americium and europium distribution ratios measured using the irradiated phases are presented in Table 1.

Table 1. Distribution ratios, $\mathrm{D}_{\mathrm{Am}}$ and $\mathrm{D}_{\mathrm{Eu}}$, determined using static irradiated ALSEP solvent and nitric acid. Organic: 0.05 M TODGA / 0.75 M HEH[EHP] / n-dodecane. Aqueous: $3 \mathrm{M}$ nitric acid.

\begin{tabular}{ccc}
$\begin{array}{c}\text { Absorbed } \\
\text { Dose, } k G y\end{array}$ & $\mathrm{D}_{\mathrm{Am}}$ & $\mathrm{D}_{\mathrm{Eu}}$ \\
\hline 0 & $290 \pm 16$ & $2200 \pm 480$ \\
25 & $270 \pm 6$ & $2000 \pm 350$ \\
50 & $290 \pm 12$ & $320 \pm 250$ \\
100 & $140 \pm 4$ & $120 \pm 6$
\end{tabular}

The decrease in the measured distribution ratios appears to be consistent with the decrease in TODGA or T2EHDGA concentration reported by Zarzana et al. ${ }^{[7]}$ ( $\sim 20 \%$ decrease at $100 \mathrm{kGy}$ absorbed dose). The americium distribution ratios obtained for the $0-50 \mathrm{kGy}$ absorbed dose samples agree reasonably well with $\mathrm{D}_{\mathrm{Am}}$ values reported by Gelis and Lumetta. ${ }^{[1]}$ Unfortunately, these authors do not report values for $\mathrm{D}_{\mathrm{Eu}}$, however, the values of $\mathrm{D}_{\mathrm{La}}$ and $\mathrm{D}_{\mathrm{Ce}}$ from $3 \mathrm{M} \mathrm{HNO}_{3}$ are approximately $\mathrm{D}_{\mathrm{La}} \sim 10$ and $\mathrm{D}_{\mathrm{Ce}} \sim 20$. Based upon the reported values of $\mathrm{D}_{\mathrm{La}}$ and $\mathrm{D}_{\mathrm{Ce}}$, the $\mathrm{D}_{\mathrm{Eu}}$ values reported in Table 1 seem unreasonably high.

Due to the apparent inconsistent data, the acid dependence of the distribution ratios for the ALSEP solvent was measured. Due to the failure of the HPGe (High Purity Germanium) detector used for gamma analysis, these extraction experiments were not analyzed. The large error associated with the values of $\mathrm{D}_{\mathrm{Eu}}$ reported in Table may be attributable to the failure of the HPGE detector system. Therefore, the eventual failure of the HPGe detector calls into question the distribution ratio data reported in Table 1.

In addition to radiochemical measurements, the concentration of the components of the ASLEP process will be determined by various analytical methods. The analytical methodology for the determination of HEH[EHP] has been developed at INL. ${ }^{[11]}$ This method utilizes sample derivatization and gas chromatography with flame ionization detection (GC-FID) to determine HEH[EHP] and its degradation products present in organic solvents.

A similar method, which does not require sample derivatization determination, was developed for TODGA analysis. A typical calibration curve TODGA determination by GC-FID is shown in Figure 2. 
The error associated with the individual data points in the plot is smaller than the data marker used. The calibration curve is linear.

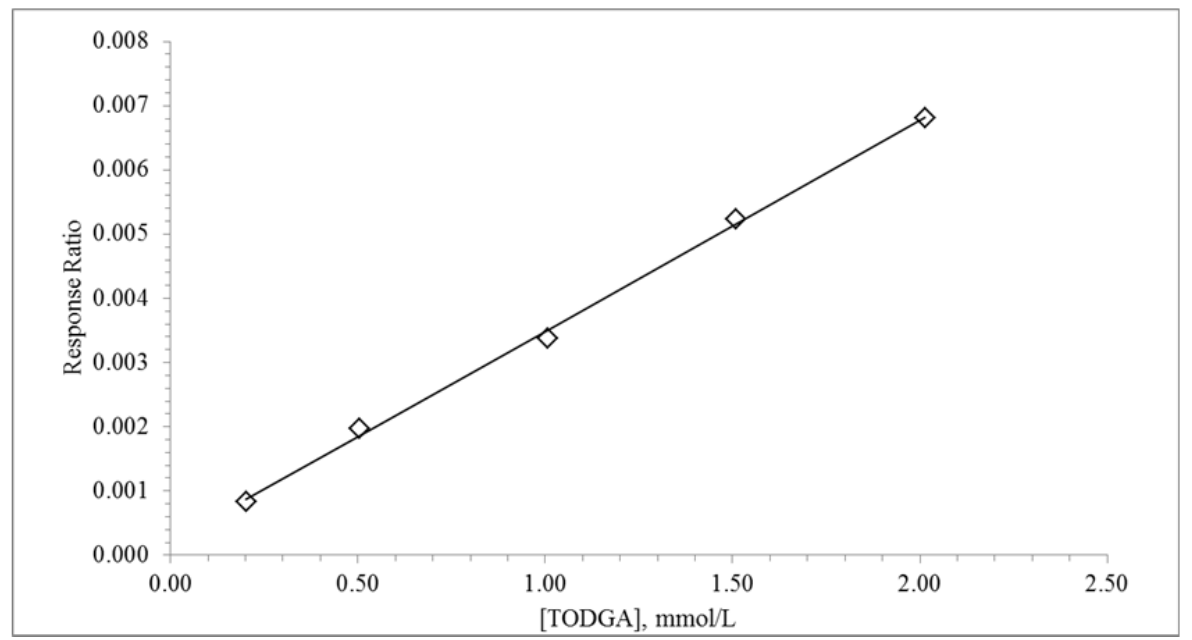

Figure 2. Calibration curve for the GC-FID analysis of TODGA. Equation of linear best-fit: $y=$ $3.281 \times 10^{-3} \mathrm{x}+2.087 \times 10^{-4}, \mathrm{R}^{2}=0.9985$.

The analysis of the irradiated ALSEP organic phases is ongoing. When the analyses are complete, the results should provide the data necessary to determine whether or the observed decrease in measured values of $\mathrm{D}_{\mathrm{Am}}$ and $\mathrm{D}_{\mathrm{Eu}}$ with increasing dose are due to the radiolytic degradation of the ALSEP solvent or due to an experimental artifact.

\section{CONCLUSIONS AND CONTINUING WORK}

Initial irradiations, up to $100 \mathrm{kGy}$ absorbed dose, of the extraction section of the ALSEP process have been completed. The organic solvent used for these experiments contained $0.05 \mathrm{M}$ TODGA and $0.75 \mathrm{M}$ HEH[EHP] dissolved in $n$-dodecane. The ALSEP solvent was irradiated while in contact with $3 \mathrm{M}$ nitric acid and the solutions were sparged with compressed air in order to maintain aerated conditions. The irradiated phases were used for the determination of americium and europium distribution ratios as a function of absorbed dose for the extraction and stripping conditions. Analysis of the irradiated phases in order to determine solvent composition as a function of absorbed dose is ongoing. Unfortunately, the failure of analytical equipment necessary for the analysis of the irradiated samples has made the consistent interpretation of the analytical results difficult.

Continuing work will include of study of the impacts of gamma radiolysis upon the extraction of actinides and lanthanides by the ALSEP solvent and the stripping of the extracted metals from the loaded solvent. The irradiated aqueous and organic phases will be analyzed in order to determine the variation in concentration of solvent components with absorbed gamma dose. Where possible, radiolysis degradation product will be identified. 


\section{REFERENCES}

1. Gelis, A.V.; Lumetta, G.J. "Actinide Lanthanide Separation Process-ALSEP" Indust.Eng. Chem. Res. 2014, 53, 1624-1631.

2. Lumetta, G.J.; Gelis, A.V.; Carter, J.C.; Niver, C.M.; Smoot, M.R. "The Actinide-Lanthanide Separation Concept" Solv. Extr. Ion Exch. 2014, 32, 333-347.

3. Zhengshui, H.; Ying, P.; Wanwu, M.; Xun, F. "Purification of organophosphorus acid extractants" Solv. Extr. Ion Exch. 1995, 13, 965-976.

4. Sehested, K., The Fricke Dosimeter. In Manual on Radiation Dosimetry; Holm, N.W., Berry, R.J., Eds. Marcel Dekker, Inc: New York, 1970, 313-317.

5. Klassen, N.V.; Shortt, K.R.; Seuntjens, J.; Ross, C.K. "Fricke dosimetry: the difference between $\mathrm{G}\left(\mathrm{Fe}^{3+}\right)$ for ${ }^{60} \mathrm{Co}$ gamma-rays and high-energy x-rays" Phys. Med. Biol. 1999, 44, 1609-1624.

6. Black, T.H. "The preparation and reactions of diazomethane" Aldrichimica Acta 1983, 16, 3-10.

7. Zarzana, C.A.; Groenewold, G.S.; Mincher, B.J.; Mezyk, S.P.; Wilden, A.; Schmidt, H.; Modolo, G.; Wishart, J.F.; Cook, A.R. "A comparison of the $\gamma$-radiolysis of TODGA and T(EH)DGA using UHPLC-ESI-MS analysis Solv. Extr Ion Exch. Submitted.

8. Sugo, Y.; Sasaki, Y.; Tachimori, S. "Studies on hydrolysis and radiolysis of N,N,N,N-tetraoctyl-3oxapentane-1,5-diamide" Radiochim. Acta 2002, 90, 161-165.

9. Sharma, J.N.; Ruhela, R.; Singh, K.K.; Kumar, M.; Janardhanan, C.; Achutan, P.V.; Manohar, S.; Wattal, P.K.; Suri, A.K. "Studies on hydrolysis and radiolysis of tetra(2-ethylhexyl) diglycolamide (TEHDGA)/isodecyl alcohol/n-dodecane solvent system" Radiochim Acta 2010, 98, 485-492.

10. Deepika, P.; Sabharwal, K.N.; Srinivasan, T.G.; Rao, P.R.V. "Studies on the use of $N, N, N^{\prime}, N^{\prime}$-tetra(2ethylhexyl) diglycolamide (TEHDGA) for actinide partitioning II: Investigation on radiolytic stability" Solv. Extr. Ion Exch. 2011, 29, 230-246.

11. Peterman, D.R.; Olson, L.G.; McDowell, R.G.; Groenewold, G.S.; Zarzana, C.A.; Bauer, W.F.; Morgan, S.J. "Investigation of the Impacts of Gamma Radiolysis on an Advanced TALSPEAK Separation" Idaho National Laboratory, FCRD-SWF-2014-000205, August 15, 2014. 